\title{
Detection of Minute Temperature Transients by Thermosensitive Neurons
}

\author{
in Ants
}

\author{
Markus Ruchty, ${ }^{1}$ Flavio Roces, ${ }^{1}$ and Christoph Johannes Kleineidam ${ }^{1,2}$ \\ ${ }^{1}$ Department of Behavioral Physiology and Sociobiology, Biozentrum, University of Würzburg, Würzburg; and ${ }^{2}$ Department of Biology, \\ University of Konstanz, Konstanz, Germany
}

\begin{abstract}
Ruchty M, Roces F, Kleineidam CJ. Detection of minute temperature transients by thermosensitive neurons in ants. $J$ Neurophysiol 104: 1249-1256, 2010. First published June 23, 2010; doi:10.1152/jn.00390.2010. The antennae of leaf-cutting ants are equipped with sensilla coeloconica that house three receptor neurons, one of which is thermosensitive. Using convective heat (air at different temperatures), we investigated the physiological characteristics of the thermosensitive neuron associated with the sensilla coeloconica in the leaf-cutting ant Atta vollenweideri. The thermosensitive neuron very quickly responds to a drop in temperature with a brief phasic increase $(50 \mathrm{~ms})$ in spike rate and thus classifies as cold receptor (ambient temperature $=24^{\circ} \mathrm{C}$ ). The short latency and the brief phasic response enable the thermosensitive neuron to follow temperature transients up to an estimated frequency of around $5 \mathrm{~Hz}$. Although the neuron responds as a cold receptor, it is extremely sensitive to warm stimuli. A temperature increase of only $0.005^{\circ} \mathrm{C}$ already leads to a pronounced decrease in the resting activity of the thermosensitive neuron. Through sensory adaptation, the sensitivity to temperature transients is maintained over a wide range of ambient temperatures $\left(18-30^{\circ} \mathrm{C}\right)$. We conclude that the thermosensitive neuron of the sensilla coeloconica is adapted to detect minute temperature transients, providing the ants with thermal information of their microenvironment, which they may use for orientation.
\end{abstract}

I N T R O D U C T I O N

The assessment of environmental temperature is crucial for small, ectotherm animals like insects because they have to respond immediately to unfavorable thermal conditions. Due to their low mass, insects heat up or cool down quickly. For instance, a $10 \mathrm{mg}$ fly exposed to direct sunlight heats up $10^{\circ} \mathrm{C}$ in $10 \mathrm{~s}$ (Heinrich 1993). Most insects exhibit a pronounced thermal preference that allows them to avoid hyper- or hypothermia. In particular, social insects show an amazingly precise thermal preference, such as during brood care. Already an offset of only $0.2^{\circ} \mathrm{C}$ from optimal brood temperature provokes the relocation of brood in ant colonies (Roces and Núñez 1989, 1995; Weidenmüller et al. 2009). Other insects, like bloodsucking bugs are also highly sensitive to thermal stimuli, which they use to find their hosts (Wigglesworth and Gillet 1934); and even species without obvious specialization to host detection show strict thermal preferences, e.g., cockroaches (Murphy and Heath 1983) or flies (Sayeed and Benzer 1996; Yamamoto 1979). For most temperature-guided behaviors of different insect species that have been studied so far, it is unclear how the temperature stimulus is transferred from the thermal source to the insects' receptors. Insects may use

Address for reprint requests and other correspondence: C. J. Kleineidam, Biology, University of Konstanz, Universitätsstraße 10, 78457 Konstanz, Germany (E-mail: christoph.kleineidam@uni-konstanz.de). radiant heat (thermal radiation) as a cue for orientation or the changing air temperature around their body (convective heat) may trigger the behavioral response.

Several physiological studies have shown that thermosensitive neurons of antennal sensilla in insects respond to both convective heat and thermal radiation (Gingl and Tichy 2001; Gingl et al. 2005; Kreiss et al. 2007; Ruchty et al. 2009). However, some insect species are known to rely mainly or even exclusively on thermal radiation as an orientation cue. In these cases, specific properties of the thermosensitive sensilla are expected to serve as adaptation to the detection of thermal radiation. One well-investigated example is the pit organ of Australian fire beetles that carries up to 80 thermosensitive sensilla. Accessory structures of these sensilla change on absorption of thermal radiation emitted at wavelengths of 3-5 $\mu \mathrm{m}$ from forest fires, resulting in a photomechanical stimulus transduction (Müller et al. 2008; Schmitz and Bleckmann 1997; Schmitz et al. 2007; Vondran et al. 1995).

In the physiological temperature range of $30-35^{\circ} \mathrm{C}$ (corresponding to longer wavelengths of $\sim 10 \mu \mathrm{m}$ ), however, thermal radiation has much less power, as indicated by the StefanBoltzmann law. Therefore the detection of differences in thermal radiation in that particular temperature range poses high demands on a sensory system. The blood-sucking bugs Triatoma infestans and Rhodnius prolixus are guided solely by the thermal radiation emitted from their endothermic hosts (Lazzari and Núñez 1989; Schmitz et al. 2000). These bugs seem to measure the distance to their host based on temperature gradients along their antennae (Lazzari 2009) and probably evaluate the size of the object by saccadic antennal movements (Flores and Lazzari 1996).

Like the triatomine bugs, leaf-cutting ants can use thermal radiation as a cue for orientation. Similar to the detection system in the bugs, ants scan their environment by fast antennal movements to detect heated objects and use them as learned landmarks (Kleineidam et al. 2007). During antennal scanning, the antennae of leaf-cutting ants can reach angular velocities of up to $3.6^{\circ} \mathrm{ms}^{-1}$ (Ehmer and Gronenberg 1997) that may generate rapid, minor temperature transients at thermosensitive sensilla.

Because the sensilla coeloconica (Sc) of leaf-cutting ants house a thermosensitive neuron, they are good candidates for providing the ants with the underlying thermal information used for orientation (Ruchty et al. 2009). Irrespective of whether thermal radiation and/or convective heat act on the antennal sensilla, the resulting temperature transients are expected to be minute and brief. To detect such stimuli, thermosensitive neurons with high temporal resolution and outstand- 
ing sensitivity are required. In this study, we investigate in detail the physiology of the thermosensitive neuron of Sc in the leaf-cutting ant Atta vollenweideri and ask whether the neuron is adapted to detect rapid and minute temperature transients. To this aim, we stimulated the neuron with brief air pulses of different temperatures and investigated whether different ambient temperatures influence its response characteristics. Based on these measurements, we were able to evaluate whether the neurons are suited to detect temperature transient that, for example, occur during the thermal landmark orientation.

\section{METHODS}

\section{Animals}

Workers of Atta vollenweideri were obtained from a laboratory colony collected in 2002 at the Reserva Ecológica El Bagual, Formosa, Argentina. The colony was reared at the Biozentrum, University of Würzburg at $25^{\circ} \mathrm{C}$ and $50 \%$ relative humidity in a $12-\mathrm{h} / 12$-h photoperiod and fed mainly with leaves of privet (Ligustrum vulgaris) and dog rose (Rosa canina). Because for the experiments only medium-sized workers from the feeding site were collected, it is assumed that only foragers were investigated.

\section{Physiology of the thermosensitive neuron}

PREPARATION AND RECORDING. The physiology of the thermosensitive neuron associated with a sensillum coeloconicum $(\mathrm{Sc})$ was investigated by extracellular recording of its neuronal activity. To obtain independent measurements, only one sensillum per specimen was investigated. Workers were mounted on a plastic holder with adhesive tape and the scapus was glued onto the holder with WhiteOut correction fluid (Tipp-Ex; Bic, Clichy, France). Under visual control and at a magnification of $\times 390$ (Leitz microscope equipped with NPL-Fluotar L25/0.35; Leitz Microsystems, Wetzlar, Germany), an electrolytically sharpened tungsten electrode was superficially inserted into the cuticle next to a single Sc using a manual micromanipulator (HS-6; Märzhäuser, Darmstadt, Germany). To achieve a good signal to noise ratio during such an extracellular recording, the reference electrode was inserted deep into the flagellum in close vicinity of the recording electrode. Recordings were band-pass filtered $(60 \mathrm{~Hz}$ to $3 \mathrm{kHz}$ ) and amplified $\times 1,000$ (Neuroprobe Amplifier 100; A-M Systems, Sequim, WA and VBF8; Kemo, Kent, UK). The electrical noise was significantly reduced using an additional digital filter (Humbug; Quest Scientific, North Vancouver, BC, Canada). Data were digitized at a sampling rate of $10 \mathrm{kHz}$ and recorded on a PC using custom-made software (LabVIEW, National Instruments, Austin, TX).

To describe the physiology of the thermosensitive neurons in terms of general response properties, response dynamics, sensitivity, and adaptation to ambient temperature, we used convective heat as a stimulus. Rapid changes in air temperature were used to assess the threshold sensitivity to step transients and, based on the responses to step transients of different amplitude $(\Delta \mathrm{T})$, dose-response curves were measured. During all measurements, a continuous airflow (flow rate $1.5 \mathrm{~L} / \mathrm{min}$ ) was blown via a glass tube $(2 \mathrm{~cm}$ inner diameter [ID] at a distance of $1 \mathrm{~cm}$ from the antenna) over the preparation. The stimulus airflow ( $5 \mathrm{~mm} \mathrm{ID}$, at a distance of $1 \mathrm{~cm}$ from the antenna) was positioned directly opposite to the tube, providing the continuous airflow (Fig. 1A). This arrangement of the two airflows allowed the injection of the stimulus airflow into the laminar continuous flow, resulting in a rapid change in temperature (step transients) at the investigated sensillum (Kleineidam et al. 2000). Air temperatures in both airflows were controlled by heat exchangers close to the outlet of the two tubes and measured with thermocouples ( $\mathrm{NiCr}-\mathrm{Ni}$, type $\mathrm{K}$; Conrad Electronics, Hirschau, Germany). The continuous airflow was

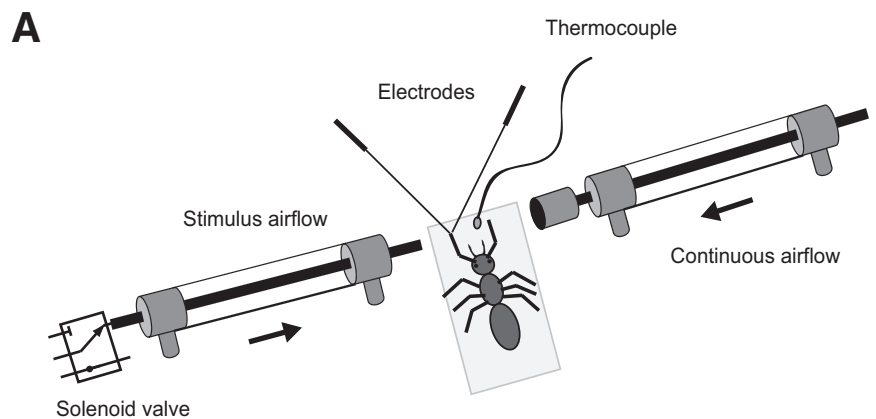

B

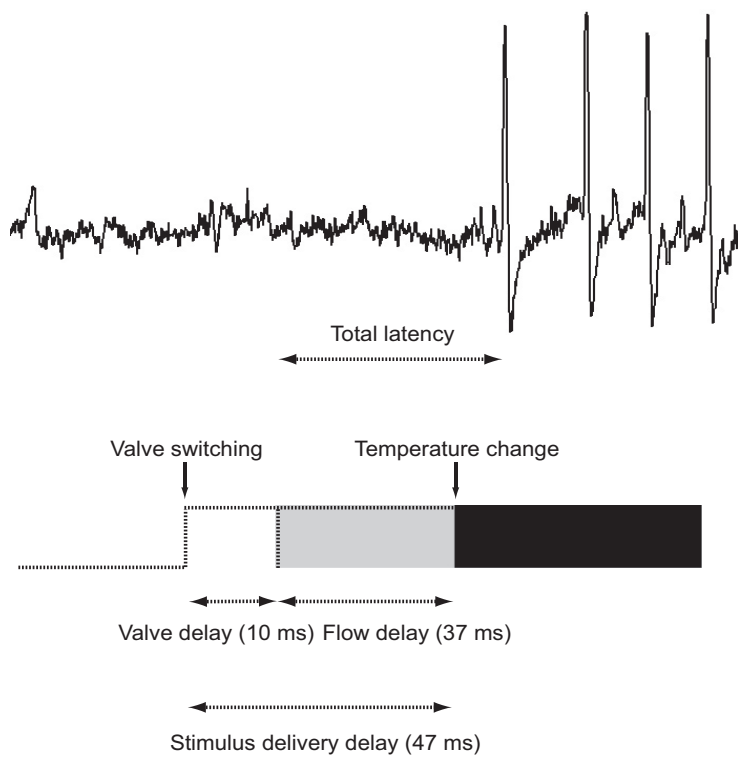

FIG. 1. Stimulation setup and calculation of response latency. $A$ : the thermosensitive neuron was stimulated with rapid changes in temperature (step transients) by switching the stimulus airflow into a laminar continuous airflow. The resulting change in temperature was measured with a thermocouple. $B$ : a valve delay of $10 \mathrm{~ms}$ and a calculated flow delay of $37 \mathrm{~ms}$ resulted in a total stimulus delivery delay of $47 \mathrm{~ms}$ until the warm or cold air puff reached the preparation. The time after switching the solenoid valve (end of valve delay) until the first action potential at peak frequency occurred was taken as a conservative measure for the response latency (total latency) of the neuron.

always kept at a temperature of $24^{\circ} \mathrm{C}$, except during the adaptation experiments. A thermocouple was placed on the Plexiglas holder close to the investigated antenna to estimate the actual stimulus temperature. The heat exchangers could be heated or cooled via two silicon tubes connected to two independent water baths (DC1; Haake, Burladingen, Germany). During the experiments the stimulus airflow was switched on for $5 \mathrm{~s}$ using a solenoid valve (valve delay $10 \mathrm{~ms}$; Lee, Westbrook, CT) controlled by the data capture software (LabVIEW).

We analyzed the response of the thermosensitive neurons to temperature stimuli in the range of $\Delta \mathrm{T}=+8^{\circ} \mathrm{C}$ to $\Delta \mathrm{T}=-14^{\circ} \mathrm{C}$ around an ambient temperature of $24^{\circ} \mathrm{C}$. In the range close to ambient temperature we used $0.1^{\circ} \mathrm{C}$ transients to describe the neurons' sensitivity in greater detail. To investigate the neurons' adaptation characteristics and the effect of changes in ambient temperature on the physiology of the thermosensitive neurons, we described dose-response curves at ambient temperatures of 18,24 , and $30^{\circ} \mathrm{C}$, respectively.

DATA ANALYSIS. During extracellular recordings from a single Sc, the recording electrode simultaneously picked up voltage signals from one to three receptor neurons. The thermosensitive neuron could be easily distinguished from the other neurons by the higher amplitude of its recorded potentials. This fact facilitated analysis of the 
response characteristics of that particular neuron. We used a voltage spike detection based on threshold, programmed in LabVIEW, to selectively detect action potentials generated by the thermosensitive neuron. From these data, we calculated the instantaneous frequency (reciprocal of the time elapsed between two consecutive action potentials). The maximum response of a neuron is described by the peak frequency that is the highest instantaneous frequency during stimulation.

We used a very conservative measure to calculate how fast the neurons respond to step transients (total latency). We calculated the flow velocity at the end of the stimulation tube being $27.37 \mathrm{~cm} / \mathrm{s}(8 \mathrm{bar}$ pressure, diameter: $5 \mathrm{~mm}$, length: $40 \mathrm{~cm}$ ), which results in a delay of $37 \mathrm{~ms}$ caused by the stimulus airflow (flow delay). Together with the valve delay of $10 \mathrm{~ms}$, the calculated stimulus delivery delay is $47 \mathrm{~ms}$ (Fig. $1 B$ ). The flow delay highly depends on the distance between the outlet of the tube and the antenna and, at our preparation, this distance could not be assessed with high accuracy. Therefore we subtracted only the valve delay and not the flow delay to calculate the total latency of the response. Thus the neuronal latency (i.e., the time between stimulus onset and peak frequency) is expected to be considerably smaller, as indicated by our measure of the total latency.

To assess the highest sensitivity of the thermosensitive neurons, we chose the stimulus delivery with the fastest, steplike temperature transients we could generate. However, such temperature transients cannot be monitored by a thermocouple system because of the mass of the thermocouple that is larger than the tip of an antenna and because the voltage signal has to be low-pass filtered to obtain an accurate measure.

We described the duration of the phasic response by subsequently measuring the time until the instantaneous frequency decreased to $66 \%$ of the peak frequency.

The response characteristics of sensory neurons can be well described by a power function (Drew and Abbott 2006). We used a model according to Stevens' power law (Stevens 1957) to iteratively calculate the dose-response relationship of the thermosensitive neurons. The function used allows us to compare the sensitivity of the thermosensitive neurons with other sensory systems, across modalities. For statistical analysis and to plot data, we used the software STATISTICA 8 (Statsoft, Tulsa, OK) and ORIGIN 8 (OriginLab, Northampton, A).

\section{RES U L T S}

The thermosensitive neurons of sensilla coeloconica $(\mathrm{Sc})$ in Atta vollenweideri have a resting activity (RA) of around 10 impulses/s $\left(\right.$ mean $=9.30, \mathrm{SD}=4.05, n=34$, at $24^{\circ} \mathrm{C}$; independent measurements). As an example of one neuron, a minute temperature increase $\left(\Delta \mathrm{T}=0.1^{\circ} \mathrm{C}\right.$; Fig. $\left.2 A\right)$ results in a phasic-tonic drop in activity and vice versa with a phasictonic increase in neuronal activity to a temperature $\operatorname{drop}(\Delta \mathrm{T}=$
A

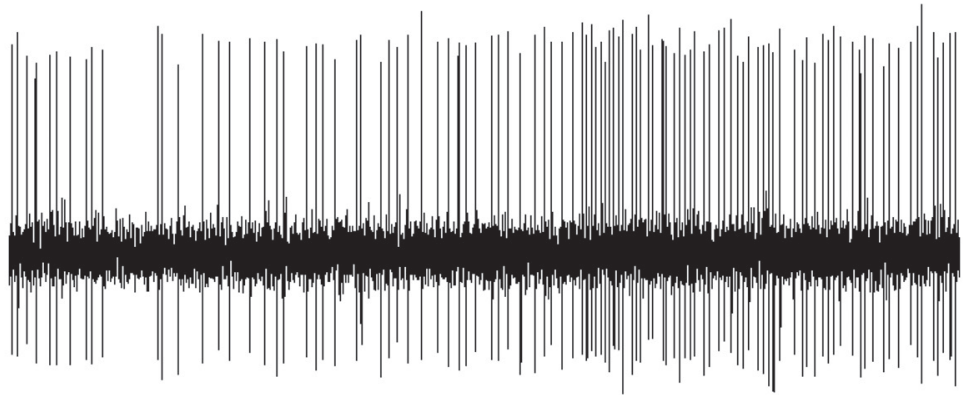

$\Delta \mathrm{T}=+0.1^{\circ} \mathrm{C}$

B

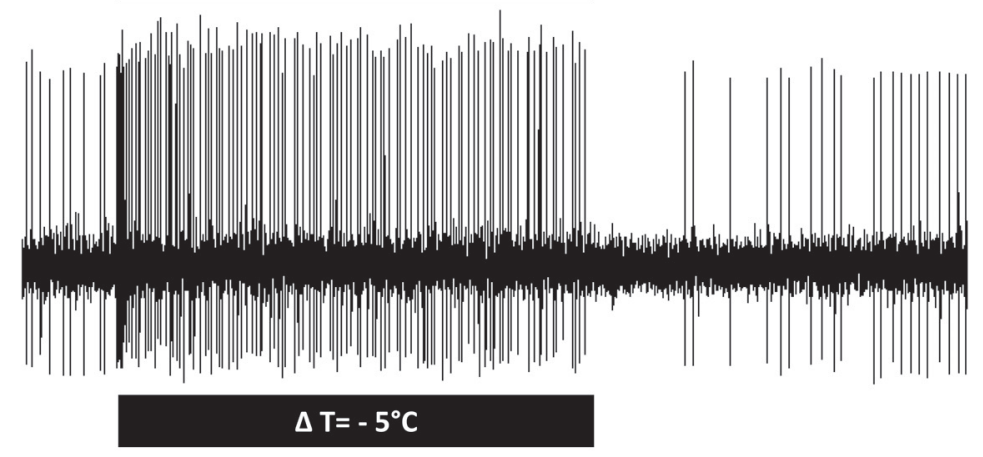

C

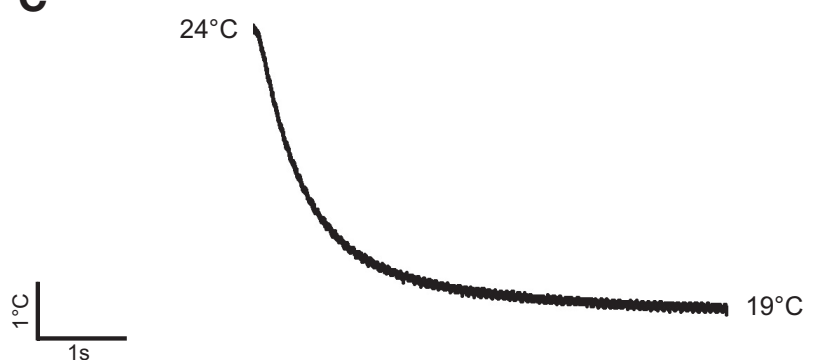

FIG. 2. General response characteristic. Example of extracellular recordings of a thermosensitive neuron associated with a sensillum coeloconicum in response to temperature transients from an ambient temperature of $24^{\circ} \mathrm{C}$. A: the thermosensitive neuron has a resting activity of about 10 impulses/s and responds to a temperature increase of $\Delta \mathrm{T}=$ $0.1^{\circ} \mathrm{C}$ with an initial cessation of neuronal activity. $B$ : a drop in temperature of $\Delta \mathrm{T}=-5^{\circ} \mathrm{C}$ causes a phasic-tonic increase in neuronal activity. The highest instantaneous frequency (peak frequency) during the phasic part of the response was $105 \mathrm{impulses} / \mathrm{s}$. Subsequently to stimulation ( $5 \mathrm{~s}$ ), the neuron ceases firing and recovers to resting activity about $3 \mathrm{~s}$ later. $C$ : the voltage signal of the thermocouple indicates a rapid onset of the temperature stimulus; however, the time course of the voltage signal does not reflect the actual temperature at the receptive site because of a much longer time constant of the measuring system compared with the neuronal response. 


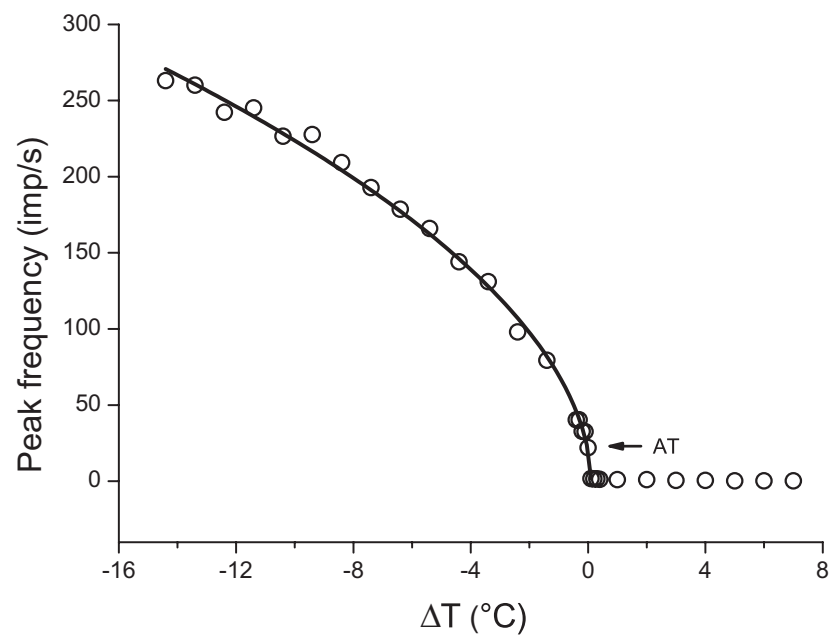

FIG. 3. Sensitivity of the thermosensitive neuron. Example of a doseresponse curve recorded at $24^{\circ} \mathrm{C}\left(=0^{\circ} \mathrm{C}\right.$ at abscissa) ambient temperature (AT, indicated by an arrow). The peak frequency is shown as a function of step transient changes from AT. The sensitivity of the neuron, indicated by the slope of the curve, is highest around AT. Using an iterative fitting function (Stevens' power function: $y=a * x^{k} ; k=0.52 ; R^{2}=0.996$ ), the sensitivity of the neuron was quantified.

$-5^{\circ} \mathrm{C}$; Fig. $2 B$ ). A change of $\Delta \mathrm{T}=-5^{\circ} \mathrm{C}$ from ambient temperature $\left(24^{\circ} \mathrm{C}\right)$ results in a peak frequency of 105 impulses/s and a maximum response of around 290 impulses/s at $\Delta \mathrm{T}=-14^{\circ} \mathrm{C}$ (Fig. 2B). Thus these neurons classify as being cold sensitive (Ruchty et al. 2009). The neurons' responses to temperature transients seem to be immediate, since the peak frequency is reached already at a time when the thermocouple first detects a change in temperature (Fig. 2C). The delayed but fast temperature transient we applied with our stimulus delivery system to measure the neurons' response onset is much faster than any technical device. Such steplike temperature transients cannot be monitored with conventional thermocouples at a temporal resolution necessary to measure the actual temperature at the receptive site, as illustrated with the temperature measurement shown in Fig. $2 C$.

\section{Sensitivity}

The thermosensitive neurons are extremely sensitive to temperature transients. An example of a dose-response curve is given in Fig. 3. The slope of the dose-response curve is low for large $\Delta \mathrm{T}$ and thus the neuron's ability to discriminate between two large but different cooling temperature transients is low. Sensitivity to small temperature steps is much higher around ambient temperature $\left(24^{\circ} \mathrm{C}\right.$; marked with an arrow in Fig. 3$)$, as shown by the steep slope of the dose-response curve.

In response to warming temperature transients of $>1{ }^{\circ} \mathrm{C}$ above ambient temperature, this neuron does not generate any action potentials during the time window analyzed ( $2 \mathrm{~s})$ and even transients as little as $0.1^{\circ} \mathrm{C}$ result in cessation of neuronal activity for about $600 \mathrm{~ms}$ (Figs. $2 A$ and 3). The dose-response curve is well described by the power function: $y=a x^{k}$, with $k=0.52\left(R^{2}=0.996\right)$. Based on the model used, the steepest slope of the dose-response curve is at stimulus intensities slightly higher than ambient temperature $\left(<0.01^{\circ} \mathrm{C}\right.$; calculated for all cooling and the smallest warming temperature transients used in the experiments). In the $\Delta \mathrm{T}>0$ range neuronal activity drops almost to zero. In the neuron shown in Fig. 3, a calculated temperature transients of only $\Delta \mathrm{T}=+0.005^{\circ} \mathrm{C}$ already leads to a decrease of $1 \mathrm{impulse} / \mathrm{s}$ (10\%) in neuronal activity, which corresponds to an extrapolated rate of change of 200 impulses $/ 1^{\circ} \mathrm{C}$.

We calculated the power function for 24 neurons to quantify and compare the sensitivity of several neurons. At an ambient temperature of $24^{\circ} \mathrm{C}$ we found $k$ values as low as 0.26 and up to 0.71 (mean $k=0.52 ; \mathrm{SD}=0.28 ; n=24$ ).

The approach using a power function to fit the doseresponse curves allows the use of the exponent $k$ (i.e., the slope of the curve) as a measure of sensitivity that can be used to compare the sensitivity of the thermosensitive neuron of Sc with receptor neurons for other sensory modalities across systems.

\section{Response latency and duration}

The response of the neurons to temperature stimulation is remarkably fast. Using our conservative measure for a number of neurons, we obtained about $46 \mathrm{~ms}$ total latency for temperature transients of $\Delta \mathrm{T}=-14^{\circ} \mathrm{C}$ (Fig. 4; mean $=46.02 \mathrm{~ms}$; $\mathrm{SD}=5.30 ; n=7)$. By subtracting the flow delay $(37 \mathrm{~ms})$ estimated from the flow velocity of the stimulus air flow (see Fig. $1 B$ ), this would result in a neuronal response latency of only $9 \mathrm{~ms}$. The response latency depends on the strength of stimulation and increases with decreasing temperature transients. About $61 \mathrm{~ms}$ pass until the peak frequency is reached at a temperature transients of $\Delta \mathrm{T}=-9^{\circ} \mathrm{C}$ (Fig. 4 ; mean $=60.63$ $\mathrm{ms} ; \mathrm{SD}=7.95 ; n=7)$ and it takes even longer at $\Delta \mathrm{T}=-4^{\circ} \mathrm{C}$ (mean $=72.25 \mathrm{~ms} ; \mathrm{SD}=11.68 ; n=7)$. The neurons' phasic response on temperature stimulation is brief. About $51 \mathrm{~ms}$ after the peak frequency is reached, the instant frequency already decreases to $66 \%$ of the peak frequency $\left(\Delta \mathrm{T}=-14^{\circ} \mathrm{C}\right.$ : mean $=50.81 \mathrm{~ms} ; \mathrm{SD}=20.94 ; n=12$ ). The length of the phasic response seems to be independent of the strength of stimulation, since both smaller steps in temperature elicit a phasic response of a similar duration (Fig. $4 ; \Delta \mathrm{T}=-9^{\circ} \mathrm{C}$ : mean $=53.06 \mathrm{~ms} ; \mathrm{SD}=18.99 ; n=12 ; \Delta \mathrm{T}=-4^{\circ} \mathrm{C}$ : mean $=50.55 \mathrm{~ms} ; \mathrm{SD}=24.23 ; n=11)$. The short latency until the peak frequency is reached and in particular the

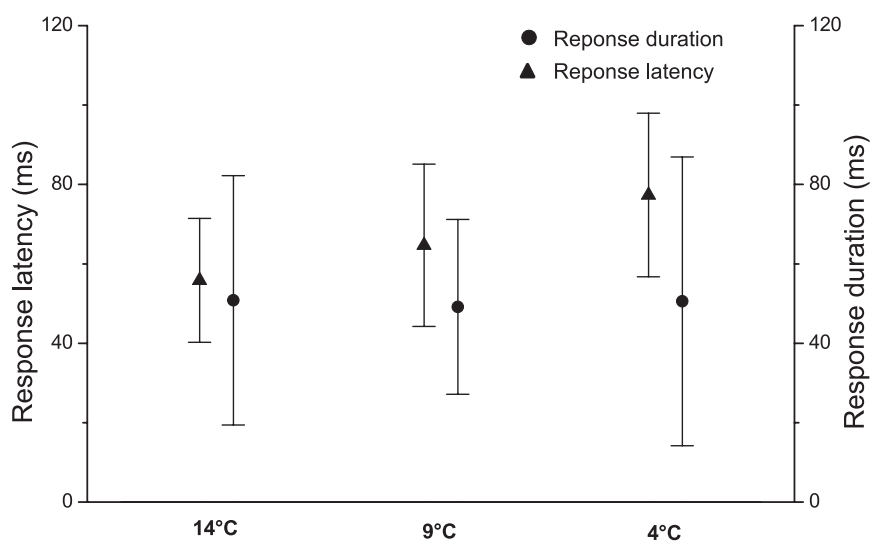

FIG. 4. Response dynamics. The phasic part of the response starts with a short latency and is brief. This indicates a high temporal resolution of the thermosensitive neuron to detect thermal fluctuations around ambient temperature. Response latency (total latency) depends on stimulus intensity (black diamonds, $n=7$, mean with $\mathrm{SD}$ as whisker), whereas the duration of the phasic response seems to be independent of stimulus intensity (black squares, $n=11$, mean with SD as whisker). 
short phasic part of the response enables the thermosensitive neuron to follow fluctuations in temperature up to an estimated frequency of around $5 \mathrm{~Hz}$.

\section{Adaptation}

To investigate how ambient temperature affects the physiology of the thermosensitive neurons, we used three ambient temperature levels $\left(18,24\right.$, and $\left.30^{\circ} \mathrm{C}\right)$ and determined doseresponse curves. The thermosensitive neurons $(n=3)$ adapt to the ambient temperatures in the range tested and maintain a high sensitivity to minute temperature transients (Fig. 5). Following a change in ambient temperature, the neurons always adapt to the same RA as before $\left(\mathrm{RA}_{\text {before }}\right.$ and $\mathrm{RA}_{\mathrm{after}}$ : $9-13$ impulses/s, $n=3$ ). In addition, the range of neuronal activity (maximum of 280 to 290 impulses/s) seems not to be affected by the ambient temperature. However, the slope of the dose-response curves differs across the three different ambient temperatures tested. We found the highest sensitivity at an ambient temperature of $24^{\circ} \mathrm{C}\left(k\right.$ at $\left.24^{\circ} \mathrm{C}: 0.22-0.24 ; n=3\right)$ followed by a slightly higher $k$ value at $18^{\circ} \mathrm{C}\left(k\right.$ at $18^{\circ} \mathrm{C}$ : $0.28-0.31 ; n=3)$. At an ambient temperature of $30^{\circ} \mathrm{C}$, we measured notably higher $k$ values (lowest sensitivity; $k$ at $30^{\circ} \mathrm{C}$ : $0.57-0.63 ; n=3$ ).

\section{I S C U S S I O N}

The thermosensitive neuron of the sensilla coeloconica (Sc) in Atta vollenweideri ants responds to a drop in temperature with a brief phasic-tonic increase in neuronal activity. The sensitivity of the neuron to temperature transients around various ambient temperatures is remarkably high. Therefore this thermosensitive system probably allows the ants to acquire information about their thermal environment by antennal scanning during thermal orientation.

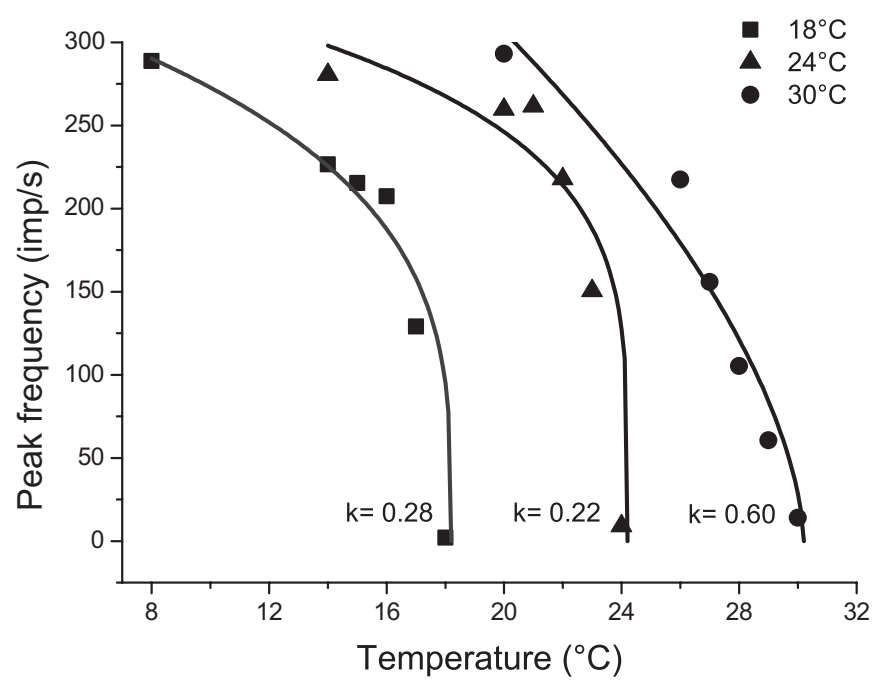

FIG. 5. Adaptation. Example of dose-response curves of one thermosensitive neuron recorded at different ambient temperatures $\left(18,24\right.$, and $\left.30^{\circ} \mathrm{C}\right)$. The thermosensitive neuron is able to detect rapid temperature transients at different ambient temperatures; however, the 3 calculated dose-response curves differ in their sensitivity ( $k$-value). The resting activity as well as the range of neuronal activity remains unaffected. The $x$-axis shows the stimulus temperature applied to the preparation. Prior to stimulation the neuron was adapted to either $18^{\circ} \mathrm{C}$ (squares), $24^{\circ} \mathrm{C}$ (diamonds), or $30^{\circ} \mathrm{C}$ (circles) ambient temperature.

\section{Sensitivity}

The course of the dose-response curves shows that the thermosensitive neuron of the Sc is extremely sensitive to temperature transients. Across the different neurons investigated, their sensitivity differs to some extent (different $k$ values) and this might lead to range fractioning of the thermosensitive sensilla. Compared with thermosensitive neurons of other insects, the sensitivity is higher by at least one order of magnitude (discrimination ability in the cave beetle and the stick insect: $0.7^{\circ}$; Loftus and Corbière-Tichané 1981; Tichy and Loftus 1987).

We used a power function to describe the dose-response curve that allows us to quantify the neuron's sensitivity. The exponent of the power function $(k)$ is a measure of sensitivity and enables comparisons across thermosensitive neurons as well as across modalities and species.

In comparison with the key senses in humans, the thermosensitive neuron of the $\mathrm{Sc}$ is as sensitive as photosensitive neurons for brightness $(k=0.33)$ and even more sensitive than odor-sensitive neurons $(k=0.6)$. Human perception of temperature and thermal radiation is, with a $k$-value of around 0.7 , considerably less sensitive than the ants' sensory neurons (Stevens 1970).

As can be derived from the good fit of the power function to our measurements, the sensitivity of the thermosensitive neuron is highest for small transients of increasing temperature $\left(0.005^{\circ} \mathrm{C}\right.$ result in $1 \mathrm{impulse} / \mathrm{s}$ change; warm sensitivity). However, the rate of action potential decreases in this case and thus the thermosensitive neuron has to be classified as a cold receptor. At first glance, both cold and warm sensitivity seem to be inconsistent, although in fact they have to be considered as an adaptation to detect minute fluctuations in temperature. The response property described for the thermosensitive neurons is comparable to that of the photosensitive neurons of the vertebrate visual system. Photosensitive neurons of the vertebrate retina are depolarized in the resting state that causes a "dark current" and hyperpolarize when stimulated by light. This physiological property, together with the signal amplification through a second-messenger cascade, results in a highly sensitive and low noise sensory system that is able to detect low stimulus intensities (Lagnado and Baylor 1992). The range in which the thermosensitive neurons can code for warming temperature transients is very limited. In response to a temperature transient of only $+0.1^{\circ} \mathrm{C}$ the neuron does not generate any action potentials for sometimes several hundred milliseconds $(600 \mathrm{~ms}$ in Fig. 2B).

When ants scan their thermal environment, fluctuating temperature might occur at the antenna. Since the thermosensitive neuron responds to temperature increases as well as decreases, minute transients in temperature can be detected.

\section{Response latency and duration}

The response of the thermosensitive neuron to temperature transients occurs very fast. The response latency (total latency) is only about half the latency measured, for example, for the thermosensitive neurons of the "little ash beetle" Acanthocnemus nigricans (Kreiss et al. 2007). However, the beetles' thermoreceptors are very different from thermoreceptors of other insects. They are adapted to receive infrared radiation 
with a spectral sensitivity around $2.8-3.5 \mu \mathrm{m}$ (Hammer et al. 2001). The fire beetle pit organs with the thermosensitive sensilla are located at the thorax of the animals and house warm-sensitive neurons (Evans 1964; Schmitz and Bleckmann 1997; Vondran et al. 1995). Each thermosensitive sensillum contains a specialized structure (cuticular sphere), which absorbs heat or thermal radiation at a particular wavelength and acts as an outer pressure vessel. Inside the sphere, a microfluidic component transduces the internal pressure onto the dendritic tip of a mechanoreceptor and thus this mechanism is termed photomechanical transduction (Müller et al. 2008; Schmitz and Bleckmann 1997; Schmitz et al. 2007; Vondran et al. 1995). In contrast, the Scs in leaf-cutting ants are antennal sensilla, which house a cold-sensitive neuron (Ruchty et al. 2009). In a previous study of the cellular and cuticular morphology of the Sc in leaf-cutting ants, we found neither a cuticular sphere in analogy to the sensilla of the pit organ in fire beetles, nor did we discover any other accessory structures that indicate a photomechanical transduction mechanism (Ruchty et al. 2009). Whether the Scs of leaf-cutting ants are also adapted to detect infrared radiation, as previously discussed, remains to be shown (Ruchty et al. 2009).

The discrepancy in response latency between the thermosensitive neurons in fire beetles and leaf-cutting ants is probably due to differences in the transduction mechanisms. The much faster response to temperature transients indicates a more direct stimulus transduction at the thermosensitive neurons associated with $\mathrm{Sc}$ in leaf-cutting ants. In the malaria mosquito Anopheles gambiae, it has recently been shown that a thermosensitive receptor channel of the TRP family (TRPA1) is expressed in Sc neurons (Wang et al. 2009). We speculate that a transmembrane ion channel probably mediates the stimulus transduction at the thermosensitive neurons of the Sc in leafcutting ants as well. It has to be shown in comparative studies on the expression of TRP ion channels whether the molecular entities of thermoreception are conserved across insect species as suggested by McKemy (2007).

The phasic response of the investigated thermosensitive neurons to temperature transients is very brief and both the short response latency and the short response duration result in an estimated temporal resolution of $5 \mathrm{~Hz}$. This response property aids in the detection of rapid fluctuations in temperature, e.g., generated by the antennal movements shown by the ants during the performance of the thermal orientation behavior (Kleineidam et al. 2007).

\section{Adaptation}

In a recent study, we could show that the thermosensitive Sc neuron rapidly adapts to long-lasting changes in ambient temperature (Ruchty et al. 2009). In the present study we show that indeed the thermosensitive neurons work as receptors for temperature transients within a wide range of at least $12^{\circ} \mathrm{C}$ around an ambient temperature of $24^{\circ} \mathrm{C}$ and that neither their resting activity nor their activity range is substantially influenced.

After adaptation to $18^{\circ} \mathrm{C}$, the sensitivity of the thermosensitive neurons is still comparable with the highest sensitivity that we found at an ambient temperature of $24^{\circ} \mathrm{C}$. The investigated subtropical leaf-cutting ant species encounters the ambient temperature range of $18-24^{\circ} \mathrm{C}$ in various different situations such as foraging, nest digging, as well as fungus- and brood-care (Bollazzi and Roces 2002; Bollazzi et al. 2008). During summer, when daytime temperatures are high, the colonies avoid hot and dry conditions by shifting their foraging activity from daytime to exclusive nighttime foraging. Thus temperatures $>30^{\circ} \mathrm{C}$ are encountered less frequently and sensory adaptation of the here described thermosensitive neurons to high temperature is probably less important. In contrast to leaf-cutting ants, other thermosensitive systems of insects that are tuned to sense temperature are less independent of ambient temperature. For example, thermosensitive neurons in locusts show increasing sensitivity with increasing temperature (Fig. 6; Ameismeier and Loftus 1988) and in cockroaches high sensitivity is restricted to a narrow range of ambient temperatures (Loftus 1968).

The adaptation properties of the thermosensitive neurons described in the present study do not provide the insects with a measure of average or steady ambient temperature. However, this important information is provided by other thermosensitive neurons, which show neuronal activity that is closely related to ambient temperature levels. Such neurons have been found in various types of sensilla and have been described, for example, in the migratory locust Locusta migratoria (Ameismeier and Loftus 1988; Waldow 1970), the cockroach Periplaneta americana (Nishikawa et al. 1992; Waldow 1970), and the honeybee Apis mellifera (Lacher 1964; Nishikawa et al. 1992). Ants also have a very accurate measure of average ambient temperature, as shown by their precise brood translocation to places with favorable thermal conditions (Roces and Núñez 1989, 1995; Weidenmüller et al. 2009). In the case of leaf-cutting ants, the symbiotic fungus is also translocated in response to unfavorable temperature conditions (Bollazzi and Roces 2002). The corresponding receptor neurons that are required for such

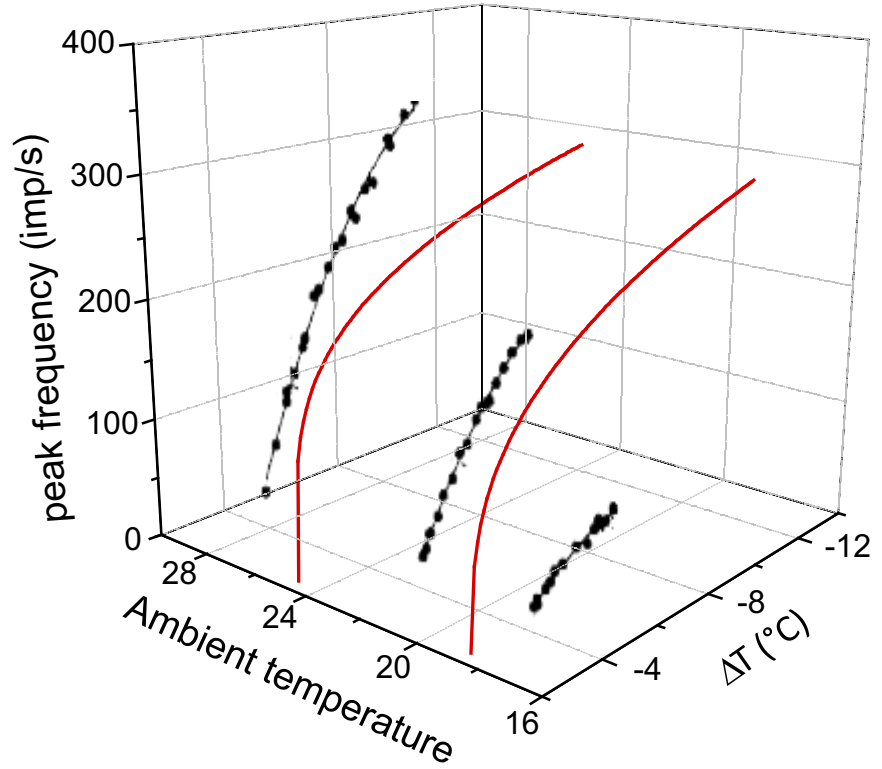

FIG. 6. Comparison of thermosensitive neurons in leaf-cutting ants and locusts. Data of the present account (Atta vollenweideri; red curves) are compared with data from a study on the locust Locusta migratoria (black curves; Ameismeier and Loftus 1988). The ants' thermosensitive neurons are more sensitive to temperature transients $(\Delta \mathrm{T})$ than the comparable thermosensitive neurons in the locust. Although the ants' thermosensitive neurons compensate well for 2 different ambient temperatures, in Locusta migratoria both the sensitivity and the range of neuronal activity depend on ambient temperature. 
thermal behavior of ants are not yet described, nor are their sensilla identified unambiguously. Likely candidate sensilla are peg in pit sensilla of the type sensilla ampullacea (Kleineidam and Tautz 1996; Kleineidam et al. 2000) or sensilla coelocapitula (Yokohari 1983).

\section{Functional adaptation for orientation behavior}

When ants move through their environment, they constantly face temperature transients either self-generated by their antennal movements or resulting from thermal discontinuities of the surroundings. The thermosensitive neurons described in this study are extremely sensitive and even minute transients can be detected. Their fast and brief response together with antennal scanning allow the ants to assess different temperatures within their microenvironment. Due to solar radiation, the microenvironment of ants is thermally structured. Unfortunately, no data are available describing the thermal microenvironment of leaf-cutting ants with high spatial resolution.

The sensitivity of the ants' thermosensitive neurons is comparable to the most sensitive animal system for detection of temperature transients hitherto described: the pit organ of snakes. It has been calculated that temperature differences as minute as $0.003^{\circ} \mathrm{C}$ can be detected by boids and pit vipers (Bullock and Diecke 1956). Thus these neurons are only marginally more sensitive than the thermosensitive neurons we described in the present study (detection of $0.005^{\circ} \mathrm{C}$ ). The snakes use their pairs of pit organs (Newman and Hartline 1982) to detect the thermal radiation emitted by their endothermic prey (Buning et al. 1981a,b) and for thermoregulatory purposes (Krochmal and Bakken 2003). Leaf-cutting ants as well use thermal radiation for orientation (Kleineidam et al. 2007) and thermal radiation has been shown to be an effective stimulus for the thermosensitive neuron associated with the Sc (Ruchty et al. 2009).

In both the pit organ of snakes and the Sc of insects, the receptor neurons respond to local temperature transients irrespective of the physical property of the stimulus (convective or radiant heat). The morphology of the pit organ of snakes serves as adaptation to the detection of thermal radiation: the pit shields the thermosensitive neurons from scattered radiation. We speculate that the tiny pit of the Sc in ants serves a similar function and, together with the remarkable physiological characteristics discovered in the present study, provides the ants with spatial information about their thermal microenvironment. Therefore we suggest that the Sc may play a prominent role in the detection of spatially distributed warm objects during foraging (Kleineidam et al. 2007).

\section{A C K N O W LED G MEN T S}

We thank A. Di Giácomo, Reserva Ecológica El Bagual (Alparamis SA, Aves Argentinas) in Formosa; P. Cichero and N. Sucunza (Parque Nacional Río Pilcomayo, APN, Formosa, Argentina); and three anonymous reviewers and R. Wehner for critically reading an earlier version of the manuscript, which led to substantial improvements.

\section{G R A N T S}

This work was supported by Deutsche Forschungsgemeinschaft Grants SFB 554, A6, and E1.

\section{I S C L O S URES}

No conflicts of interest, financial or otherwise, are declared by the author(s).

\section{REFERENCES}

Ameismeier F, Loftus R. Response characteristics of cold cell on the antenna of Locusta migratoria L. J Comp Physiol A Sens Neural Behav Physiol 163: 507-516, 1988.

Bollazzi M, Kronenbitter J, Roces F. Soil temperature, digging behaviour, and the adaptive value of nest depth in South American species of Acromyrmex leaf-cutting ants. Oecologia 158: 165-175, 2008.

Bollazzi M, Roces F. Thermal preference for fungus culturing and brood location by workers of the thatching grass-cutting ant Acromyrmex heyeri. Insect Soc 49: 153-157, 2002.

Bullock TH, Diecke FPJ. Properties of an infra-red receptor. J Physiol 134: 47-87, 1956.

Buning TD, Terashima S, Goris RC. Crotaline pit organs analyzed as warm receptors. Cell Mol Neurobiol 1: 69-85, 1981a.

Buning TD, Terashima S, Goris RC. Python pit organs analyzed as warm receptors. Cell Mol Neurobiol 1: 271-278, 1981b.

Drew PJ, Abbott LF. Models and properties of power-law adaptation in neural systems. J Neurophysiol 96: 826-833, 2006.

Ehmer B, Gronenberg W. Antennal muscles and fast antennal movements in ants. J Comp Physiol B Biochem Syst Environ Physiol 167: 287-296, 1997.

Evans WG. Infra-red receptors in Melanophila acuminata Degeer (Letter). Nature 202: 211, 1964.

Flores GB, Lazzari CR. The role of the antennae in Triatoma infestans: orientation towards thermal sources. J Insect Physiol 42: 433-440, 1996.

Gingl E, Hinterwirth A, Tichy $\mathbf{H}$. Sensory representation of temperature in mosquito warm and cold cells. J Neurophysiol 94: 176-185, 2005.

Gingl E, Tichy H. Infrared sensitivity of thermoreceptors. J Comp Physiol A Sens Neural Behav Physiol 187: 467-475, 2001.

Hammer DX, Schmitz H, Schmitz A, Rylander HG, Welch AJ. Sensitivity threshold and response characteristics of infrared detection in the beetle Melanophila acuminata (Coleoptera: Buprestidae). Comp Biochem Physiol A Mol Integr Physiol 128: 805-819, 2001.

Heinrich B. The Hot-Blooded Insects: Strategies and Mechanisms of Thermoregulation. Berlin: Springer-Verlag, 1993, p. 601.

Kleineidam C, Romani R, Tautz J, Isidoro N. Ultrastructure and physiology of the $\mathrm{CO}_{2}$ sensitive sensillum ampullaceum in the leaf-cutting ant Atta sexdens. Arthropod Struct Dev 29: 43-55, 2000.

Kleineidam C, Tautz J. Perception of carbon dioxide and other "air-condition" parameters in the leaf cutting ant Atta cephalotes. Naturwissenschaften 83: 566-568, 1996.

Kleineidam CJ, Ruchty M, Casero-Montes ZA, Roces F. Thermal radiation as a learned orientation cue in leaf-cutting ants (Atta vollenweideri). J Insect Physiol 53: 478-487, 2007.

Kreiss E, Schmitz H, Gebhardt M. Electrophysiological characterisation of the infrared organ of the Australian "Little Ash Beetle" Acanthocnemus nigricans (Coleoptera, Acanthocnemidae). J Comp Physiol A Neuroethol Sens Neural Behav Physiol 193: 729-739, 2007.

Krochmal AR, Bakken GS. Thermoregulation is the pits: use of thermal radiation for retreat site selection by rattlesnakes. J Exp Biol 206: 25392545, 2003.

Lacher V. Elektrophysiologische Untersuchungen an einzelnen Rezeptoren für Geruch, Kohlendioxyd, Luftfeuchtigkeit und Temperatur auf den Antennen der Arbeitsbiene und der Drohne (Apis mellifica L). Z Vergl Physiol 48: 587-623, 1964.

Lagnado L, Baylor D. Signal flow in visual transduction. Neuron 8: 9951002, 1992.

Lazzari CR. Orientation towards hosts in haematophagous insects: an integrative perspective. In: Advances in Insect Physiology, edited by Simpson SJ, Casas J. London: Elsevier/Academic Press, 2009, vol. 37, p. 1-58.

Lazzari CR, Núñez JA. The response to radiant heat and the estimation of the temperature of distant sources in Triatoma infestans. J Insect Physiol 35: 525-529, 1989.

Loftus R. Response of antennal cold receptor of Periplaneta americana to rapid temperature changes and to steady temperature. Z Vergl Physiol 59: 413-455, 1968.

Loftus R, Corbière-Tichané G. Antennal warm and cold receptors of the cave beetle, Speophyes lucidulus Delar, in sensilla with a lamellated dendrite. 1. Response to sudden temperature-change. J Comp Physiol 143: 443-452, 1981.

McKemy DD. Temperature sensing across species. Pflügers Arch 454: 777791, 2007.

Müller M, Olek M, Giersig M, Schmitz H. Micromechanical properties of consecutive layers in specialized insect cuticle: the gula of Pachnoda marginata 
(Coleoptera, Scarabaeidae) and the infrared sensilla of Melanophila acuminata (Coleoptera, Buprestidae). J Exp Biol 211: 2576-2583, 2008.

Murphy BF, Heath JE. Temperature selection and central temperature sensitivity in the cockroach, Periplaneta americana. Am Zool 23: 916, 1983

Newman EA, Hartline PH. The infrared vision of snakes. Sci Am 246: 116-125, 1982.

Nishikawa M, Yokohari F, Ishibashi T. Response characteristics of 2 types of cold receptors on the antennae of the cockroach, Periplaneta americana L. J Comp Physiol A Sens Neural Behav Physiol 171: 299-307, 1992.

Roces F, Núñez JA. Brood translocation and circadian variation of temperature preference in the ant Camponotus mus. Oecologia 81: 33-37, 1989.

Roces F, Núñez JA. Thermal sensitivity during brood care in workers of 2 Camponotus ant species: circadian variation and its ecological correlates. $J$ Insect Physiol 41: 659-669, 1995.

Ruchty M, Romani R, Kuebler LS, Ruschioni S, Roces F, Isidoro N, Kleineidam CJ. The thermosensitive Sensilla coeloconica of leaf-cutting ants (Atta vollenweideri). Arthropod Struct Dev 38: 195-205, 2009.

Sayeed O, Benzer S. Behavioral genetics of thermosensation and hygrosensation in Drosophila. Proc Natl Acad Sci USA 93: 6079-6084, 1996.

Schmitz A, Sehrbrock A, Schmitz H. The analysis of the mechanosensory origin of the infrared sensilla in Melanophila acuminata (Coeloptera; Buprestidae) adduces new insight into the transduction mechanism. Arthropod Struct Dev 36: 291-303, 2007.

Schmitz H, Bleckmann H. Fine structure and physiology of the infrared receptor of beetles of the genus Melanophila (Coleoptera : Buprestidae). Int J Insect Morphol Embryol 26: 205-215, 1997.

Schmitz H, Trenner S, Hofmann MH, Bleckmann H. The ability of Rhodnius prolixus (Hemiptera; Reduviidae) to approach a thermal source solely by its infrared radiation. J Insect Physiol 46: 745-751, 2000.
Stevens SS. On the psychophysical law. Psychol Rev 64: 153-181, 1957.

Stevens SS. Neural events and psychophysical law. Science 170: 1043-1050, 1970.

Tichy H, Loftus R. Response characteristics of a cold receptor in the stick insect Carausius morosus. J Comp Physiol A Sens Neural Behav Physiol 160: 33-42, 1987.

Vondran T, Apel KH, Schmitz H. The infrared receptor of Melanophila acuminata De Geer (Coleoptera: Buprestidae): Ultrastructural study of a unique insect thermoreceptor and its possible descent from a hair mechanoreceptor. Tissue Cell 27: 645-658, 1995.

Waldow U. Electrophysiological investigations of moist, dry and cold receptors on antenna of the migratory locust. Z Vergl Physiol 69: 249-283, 1970.

Wang GR, Qiu YT, Lu T, Kwon HW, Pitts RJ, Van Loon JJA, Takken W, Zwiebel LJ. Anopheles gambiae TRPA1 is a heat-activated channel expressed in thermosensitive sensilla of female antennae. Eur J Neurosci 30: 967-974, 2009.

Weidenmüller A, Mayr C, Kleineidam CJ, Roces F. Preimaginal and adult experience modulates the thermal response behavior of ants. Curr Biol 19: 1897-1902, 2009.

Wigglesworth VB, Gillet JD. The functions of the antennae in Rhodnius prolixus (Hemiptera) and the mechanism of orientation to the host. $J$ Exp Biol 11: 120-139, 1934

Yamamoto A. Variation of temperature preference among Drosophila species. Jpn J Genet 54: 475, 1979.

Yokohari F. The coelocapitular sensillum, an antennal hygroreceptive and thermoreceptive sensillum of the honey bee, Apis mellifera. Cell Tissue Res 233: $355-365,1983$ 